\title{
Realistic lonosphere: real-time ionosonde service for ISWI
}

\author{
Ivan A. Galkin ${ }^{1}$, Bodo W. Reinisch ${ }^{2,3}$, and Dieter Bilitza ${ }^{4,5}$ \\ ${ }^{1}$ Space Science Laboratory, University of Massachusetts, Lowell, MA, US, \\ ${ }^{2}$ Dept. Environmental, Earth and Atmospheric Sci., Uni of Massachusetts, Lowell, MA, US \\ ${ }^{3}$ Lowell Digisonde International, LLC, Lowell, MA, USA, \\ ${ }^{4}$ Department Physics and Astronomy, George Mason University, Fairfax, VA, USA \\ ${ }^{5}$ Heliospheric Phys. Lab., NASA Goddard Space Flight Center, Greenbelt, Maryland, USA
}

E mail (Ivan_Galkin@uml.edu).

Accepted: 25September 2018

\begin{abstract}
lonosondes have remained the main provider of continuous "ground-truth" observations of the subpeak ionospheric plasma density, available for assimilation in weather models with only a few minutes latency from the measurement. A "quiet revolution" in ionosonde networks and systematic efforts to expand the ionosonde toolbox for specification of ionospheric structure and dynamics have amounted to a Realistic lonosphere (RION) program started in 2017. RION is an ISWI instrument suite dedicated to continuing accurate and prompt nowcast of the 3D global plasma density distribution in Earth's subpeak ionosphere, based on the real-time data feeds from a global network of ionosondes with installations in 26 countries. The RION suite is more than just a multi-nation coordinated data sharing repository for experts; it is a wide-audience, high performance data center that synthesizes a live view of the current ionosphere and provides tools for its exploration and practical use. The paper reviews RION in its combination of several remote sensing, modeling, and computer science components, including the Global lonosphere Radio Observatory (GIRO) and an online data processing and dissemination center with an open data portal at http://giro.uml.edu.
\end{abstract}

(c) 2018 BBSCS RN SWS. All rights reserved

Keywords: IHY2007, ISWI

\section{Introduction}

The objective of the United Nations International Space Weather Initiative (ISWI) is to develop scientific insight for the understanding, reconstruction, and forecast of the near-Earth space weather in a global international cooperation of scientists and coordinated instrumentation and data systems. The Realistic Ionosphere (RION) is an ISWI instrument suite whose objective is to provide an accurate and prompt nowcast of the $3 \mathrm{D}$ global plasma density distribution in the subpeak ionosphere using highfrequency (HF) ionospheric sounding technology. RION includes several remote sensing, modeling, and computer science components

\section{Components of Realistic lonosphere}

\subsection{GIRO: Global lonosphere Radio Observatory}

A "quiet revolution in sensor networks", as data visionaries called it in 2003, has played its enabling role in transforming the disjointed ionosonde observatories into a real-time, automatic, collaborative space weather resource. Over 60 ionosondes in 26 countries currently contribute their data in near real-time (nRT) to the Global Ionosphere Radio Observatory (GIRO) (Reinisch and Galkin, 2011). GIRO is a multi-nation coordinated network of high-frequency (HF) radars, i.e., ionosondes, providing nRT lowlatency measured data of the subpeak ionospheric plasma density, including raw and derived data products with public dissemination via the Open Data Portal at http://giro.uml.edu (Figure 1).

\subsection{Vertical-incidence lonograms and IRTAM 3D}

All ionosondes contributing their data to GIRO perform regular vertical-incidence (VI) sounding of the ionosphere to record VI ionograms, usually every 5 or 15 minutes. The ionogram echo traces are automatically scaled (e.g., Reinisch and Huang, 1983; Wright et al., 1998; Galkin et al., 2008; Pezzopane et al., 2010), and inverted to the vertical real-height electron density profile (EDP) (Reinisch and Huang, 1983, 2001; Titheridge, 1985; Zabotin et al., 2006; Scotto, 2007). The standard URSI-specified scaled ionospheric characteristics like the F2 layer peak electron density and height, foF2 and hmF2, etc. (e.g., Piggott and Rawer, 1978), and the EDP data are ingested in

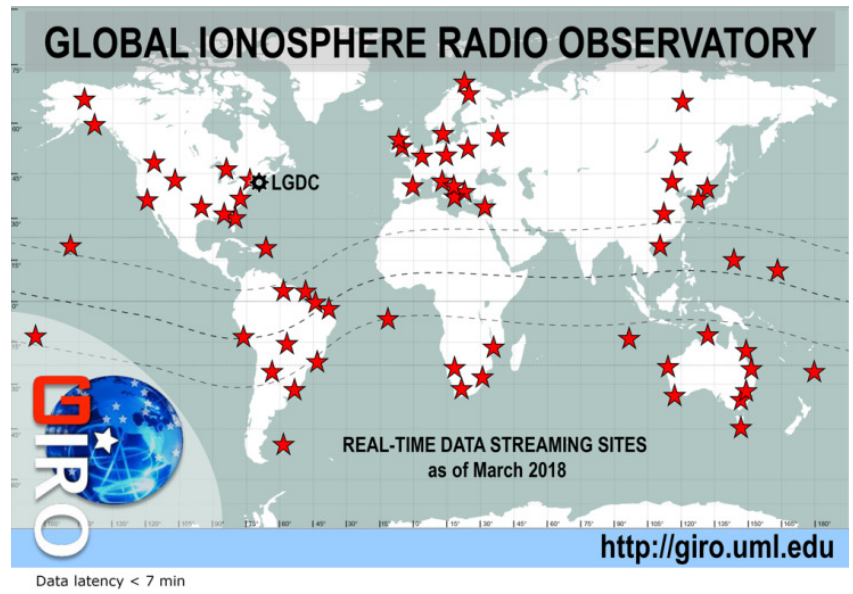

Figure 1. Global lonosphere Radio Observatory with near real-time data feeds to Realistic lonosphere. LGDC is the Lowell GIRO Data Center at the University of Massachusetts Lowell.

$\mathrm{nRT}$ in the Lowell Digital Ionogram Database (DIDBase) (Khmyrov et al., 2008) for subsequent assimilation in the "IRIbased Real Time Assimilative Model" (IRTAM) (Galkin et al., 2011).

IRTAM 3D is a global 3D empirical nowcast of the ionospheric plasma density based on a Real-Time IRI technique of smooth transformation of the background International Reference Ionosphere (IRI) climatological model (Bilitza et al., 2017; http://irimodel.org) into the optimal match with the GIRO measurements. The quiet-time-average 3D IRI model provides 2D global empirical maps of the parameters that define the vertical 1D profile of the electron density $\mathrm{Ne}$ (Bilitza et al., 2000). Of all $\mathrm{Ne}$ function parameters in IRI, the peak density and height of the F2 layer, $\mathrm{NmF} 2$ and hmF2, as well as the thickness and shape factor of the bottomside F2 layer, B0 and B1 (Ramakrishnan and Rawer, 1972; Bilitza et al., 2000; Reinisch and Huang, 1998; Altadill et al., 2009) deviate from the average quiet-time behavior most. These four parameters are replaced by their real-time updates to produce IRTAM 3D nowcast. The updates are issued every 
15 minutes with 7.5 minute latency from the GIRO ionogram measurements.

Each of the four IRTAM 2D maps of profile parameters is built by replacing the original constant coefficients of the diurnalspatial expansion in IRI with adjusted values, while keeping the rest of IRI formalism intact. The resulting weather maps preserve the key features of the electron density as captured by the IRI climatology, while applying smooth transformations to the maps so that they match the preceding 24-hour history of observations at GIRO sites. This data assimilation technique is essentially 4dimentional (4D-Var) as it considers the ionosphere in terms of its diurnal harmonics, adjusting each harmonic individually by inspecting the 24-hour history of measurements prior to nowcast time (Galkin et al, 2012). The resulting assimilation method, "Non-linear Error Correction Technique for Associative Restoration" (NECTAR), has a significant spatial prediction capability to restore the ionospheric weather effects over nocoverage areas of GIRO. Statistical validation studies with control sites suggest that the effectiveness of such spatial prediction varies substantially depending on the geometry of the ionosonde network; missing data are more likely to be restored from the neighboring GIRO sites if these are located in the similar latitude sector over distances up to $2000 \mathrm{~km}$.

The IRTAM 3D is useful in a variety of operational, scientific and educational scenarios. It provides a rapid insight into the deviation of the ionospheric conditions from their expected climatological behavior, serves as a background model to secondary computations such as HF ray-tracing, and supports decision making that relies on the knowledge of the current ionosphere state, e.g., in planning EVA spacewalks on ISS (Hartman et al., 2018). For academic studies, the Lowell GIRO Data Center (LGDC) operates an open access database of retrospective IRTAM computations with web portal at http://giro.uml.edu/GAMBIT/, covering the period from the year 2000 to current time. Figure 2 shows the example 2D IRTAM maps for foF2, hmF2, B0, and B1.

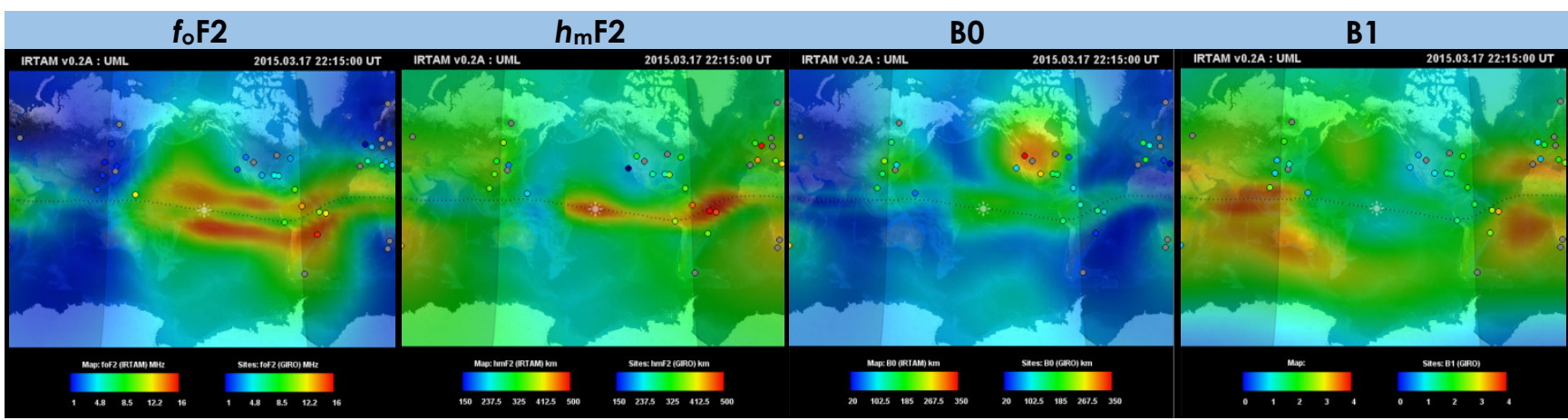

Figure 2. Global ionospheric weather maps computed by IRTAM at 15 min cadence.
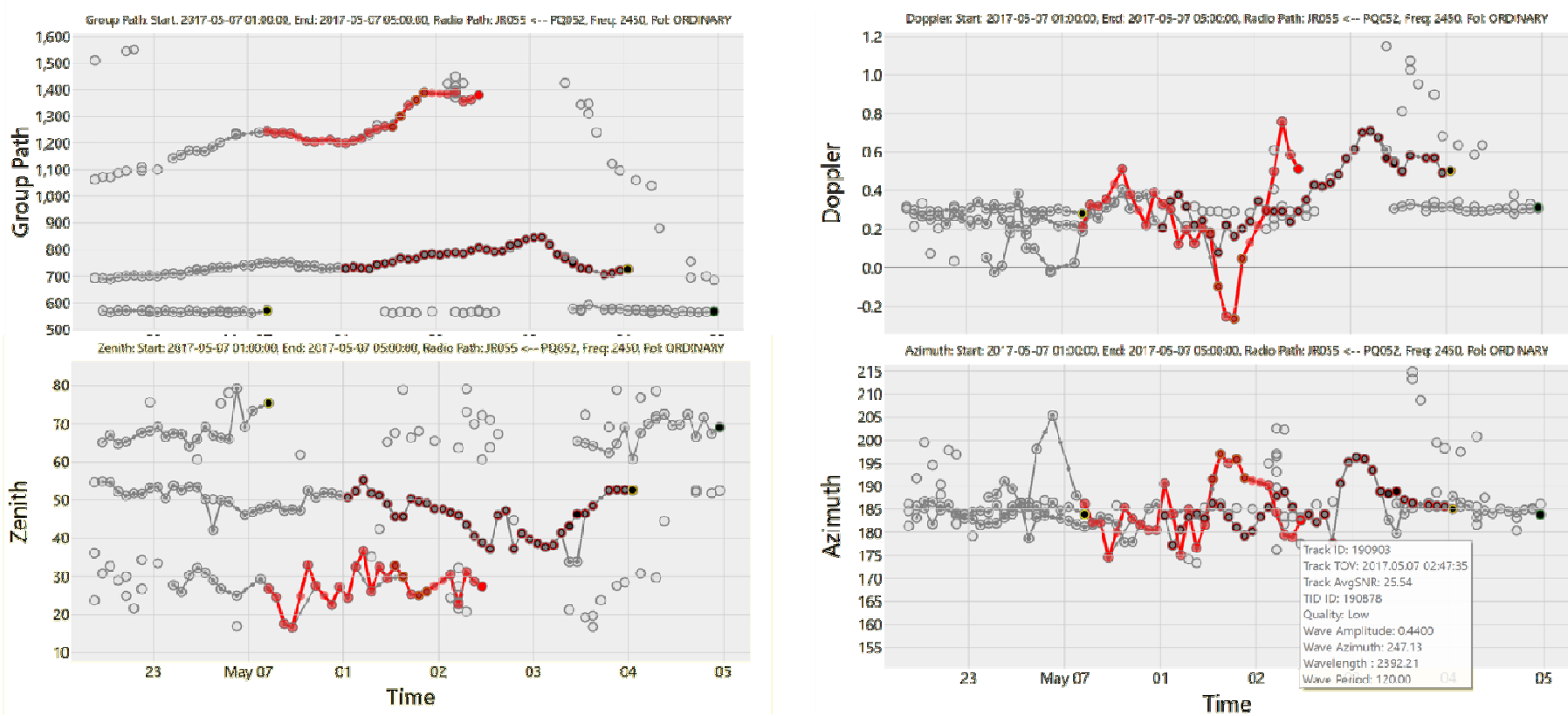

Figure 3. Example TID signatures in records of signal variations for the D2D ionospheric HF link from thePruhonice DPS4D to the Juliusruh DPS4D, May 6-7, 2017: detection and evaluation of a large-scale 120-minute 44\% TID, traveling in SSW direction. Tracks of signal variations (red lines) are extracted automatically using a human vision model ANNAE.

\subsection{TID Explorer}

Traveling Ionospheric Disturbance (TID) Explorer (Verhulst et al., 2017; Reinisch et al., 2018) is a TID detection and evaluation system based on the Doppler-Frequency-Angular Sounding (FAS) sensing method (Paznukhov et al., 2012) between two Digisonde DPS4D instruments, "D2D" configuration (Reinisch et al., 2009). TID Explorer provides nowcast and forecast of traveling ionospheric disturbances: wave-like perturbations of plasma density associated with the propagation of the atmospheric gravity waves in the neutral atmosphere in response to triggering events that can be natural (earthquake, tsunami, rapid heating of auroral oval, volcano eruption) or artificial (powerful explosion, nuclear weapon test, rocket launch). The FAS method allows full specification of the TID ensemble, including its amplitude, period, and the $\mathbf{K}$ vector of propagation. The TID characteristics are derived from the measured variations 
of the signal properties: group path $\rho$, Doppler frequency $f_{\mathrm{D}}$, and angle of arrival expressed as elevation $\varepsilon$ (or zenith angle) and azimuth $\beta$ (Reinisch et al., 2018). The group path is defined by $\rho=c \cdot \tau$, i.e., $\rho$ is equal to the measured pulse propagation time $\tau$ multiplied by the speed of light in vacuum. Figure 3 presents an example of a 44\% TID detected with the D2D link from Pruhonice, Czech Republic to Juliusruh, Germany (512 km ground distance) during high TID activity between 00 and 04 UT on May 7, 2017.

Intelligent systems are used for signal clustering and tracking (Galkin et al., 2008; Reinisch et al., 2018) in the multi-path propagation environment of the D2D radio link. A pilot TID warning system based on TID Explorer computations is operational at http://tid.space.noa.gr based on the network of DPS4D observatories in Europe.

\subsection{Sky-LITE: Skymapping for Local lonosphere Tilt Evaluation}

Single-site measurements of the reflected signal properties (time of travel, Doppler frequency, and angle of arrival) are called, for historic reasons, vertical-incidence Doppler skymaps, or simply vertical skymaps. The "skymap" (Figure 4) is simply a common visual presentation of the acquired directional measurements in polar coordinates of the zenith and azimuth angles of arrival; such presentation resembles images from all-sky cameras (e.g., Sales et al., 1996). In Figure 4, the Doppler frequency of each echo signal is indicated by color. Echo signals in the vertical skymaps rarely arrive exactly from zenith because of prevailing tilts and plasma irregularities causing reflections back to the ionosonde from off-vertical directions. The Doppler skymapping is therefore a sensitive tool for detection and characterization of disturbed plasma conditions at various scales (Reinisch et al., 1998; 2005). In particular, the 3D vector of prevailing motion of such irregular plasma structures over the observatory site can be regularly computed from the individual signatures of signal propagation. Such "bulk" plasma velocity vector estimate (shown in Figure 4 with the arrow symbols on the skymap) has been validated in comparisons to the incoherent scatter radar reference velocities (e.g., Bertoni et al., 2006; and others) to confirm its confident evaluation of the characteristic plasma dynamics; e.g., extent of the vertical uplift during the prereversal enhancement at low latitudes (Abdu et al., 2006), the convection cell structure in the polar regions (Scali et al., 1995), and others.

The center-of-gravity computation of the local ionospheric tilt angle proved to be instrumental in the evaluation of the horizontal gradients in the ionosphere for the purpose of improved raytracing (Huang and Reinisch, 2006). Line-of-sight Doppler frequency of the skymap signals recorded above and below the ionospheric duct created by HF-heating were used to evaluate the expansion velocities of the artificially created plasma structures (Vartanyan et al., 2012).

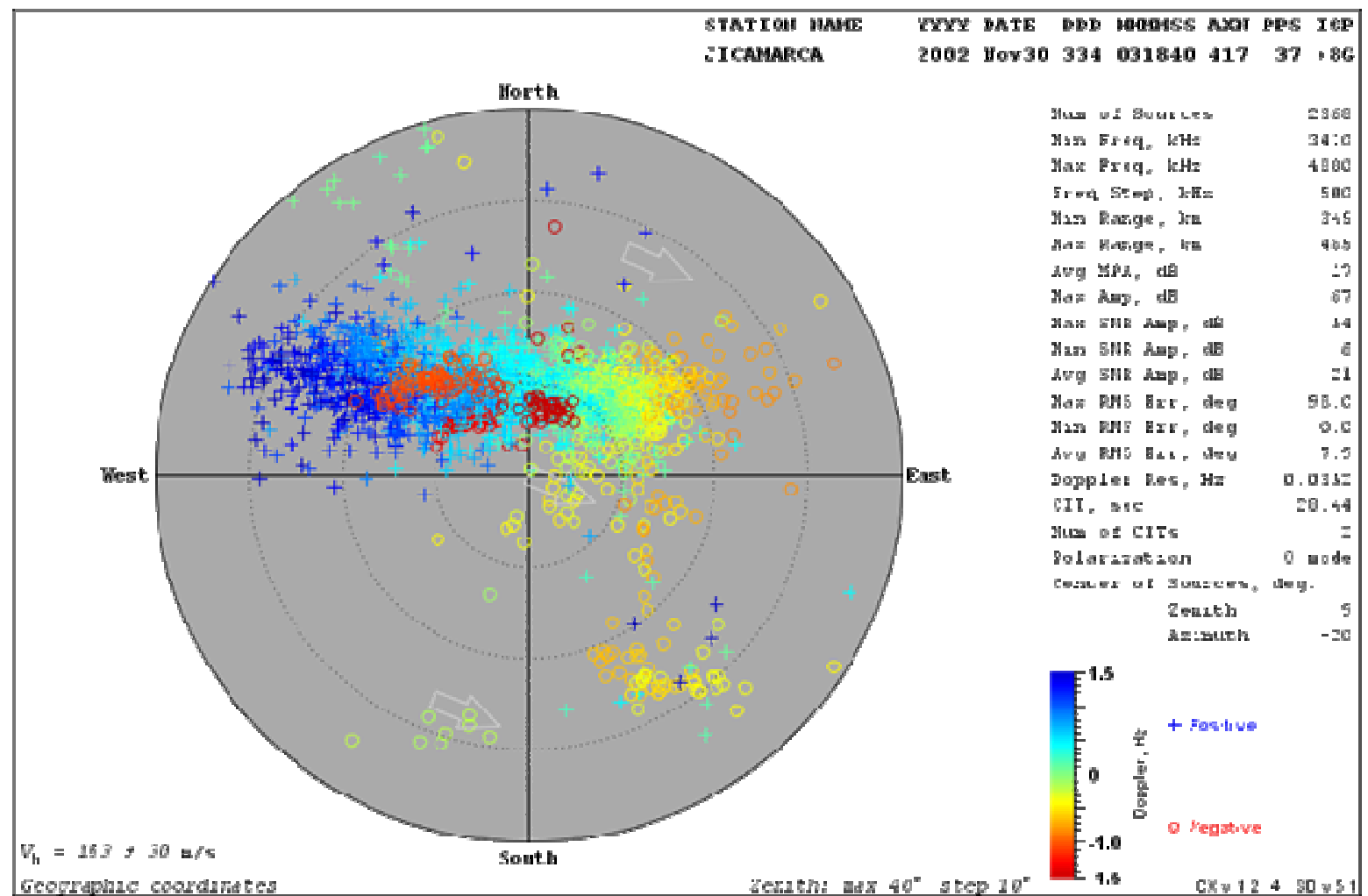

Figure 4: Real time skymap presentation of reflected signal properties: angle of arrival in polar coordinates, and Doppler frequency (color), recorded at Jicamarca, Peru. 


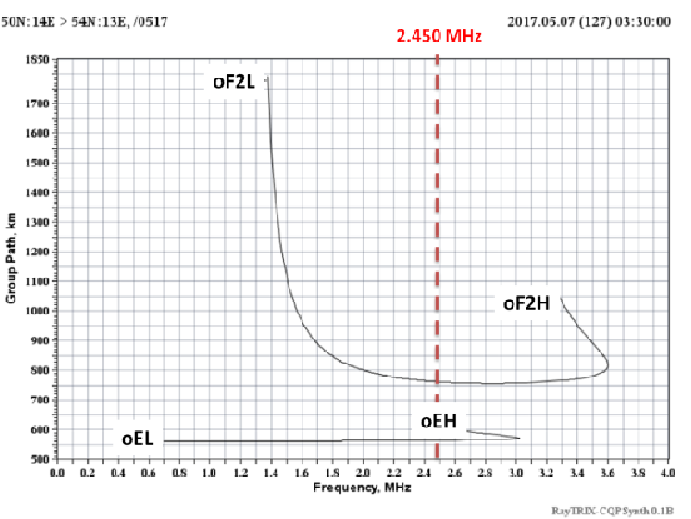

(a)

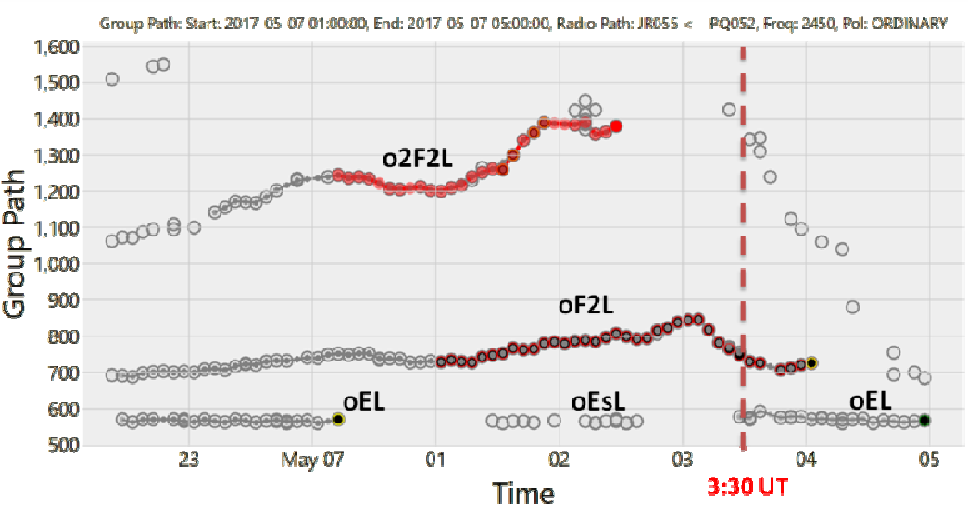

(b)

Figure 5: RayTRIX oblique ionogram synthesizer based on raytracing via CQP model fitted to the IRTAM EDP for the Pruhonice to Juliusruh radio link (517 km). (a) Synthesized oblique ionogram on May 7, 2017 03:30 UT showing presence of oF2L and oEL modes at $2.450 \mathrm{MHz}$. (b) Group path measurements at $2.450 \mathrm{MHz}$ during May6-7, 2017 showing presence of oF2L and oEL modes at 3:30 UT.

\subsection{RayTRIX: Ray-Tracing through Realistic lonosphere}

RayTRIX performs numerical HF signal raytracing (Huang and Reinisch, 2006) through the ionospheric channel specified by IRTAM, Sky-LITE, and TID Explorer. Figure 5 illustrates RayTRIX computations for the radio link and time period shown in Figure 4.

In Figure 5, the left panel displays RayTRIX computation of the oblique ionogram traces based on analytical raytracing through composite quasi-parabolic (CQP) layer model (Croft and Hoogasian, 1968) fitted to IRTAM 3D model specification obtained for the mid-path point of Pruhonice to Juliusruh radio link on May 7, 2017 03:30 UT. The synthesized ionogram shows the presence of single-hop O-wave signal propagation via $\mathrm{E}$ and $\mathrm{F}$ layers at the time of computation. The right panel is a copy of the fixed-frequency measurement display of group path in Figure 4 that is manually labeled with propagation mode identifications obtained by comparison with the synthetic ionogram. The measurements show the presence of the single $\mathrm{O}$-wave signal propagation via $\mathrm{E}$ and $\mathrm{F}$ layers at the time of the synthesizer run shown in the left panel (a).

RayTRIX provides a research environment for studying wave propagation effects associated with the realistic ionosphere model that accounts for current conditions, local ionospheric tilts, and traveling ionospheric disturbances. Impacted applications of the RayTRIX include over-the-horizon radars, direction finding, HF geolocation, and HF communications.

\subsection{Synchronized oblique sounding between DPS4D ionosondes}

Operating synchronized receivers at distances up to many hundred kilometers around a single transmitting ionosonde generate oblique ionograms for each transmitter-receiver link. In Figure 6, the DPS4D at Millstone Hill $\left(42.6^{\circ} \mathrm{N}, 288.5^{\circ} \mathrm{E}\right)$ acts as the synchronized receiver for the transmissions of the DPS4D at Wallops Island (624 km ground distance). Since the Millstone Hill DPS4D is also transmitting, its ionogram shows both the VI echo traces and $\mathrm{OI}$ echo traces of the Wallops Island transmissions.

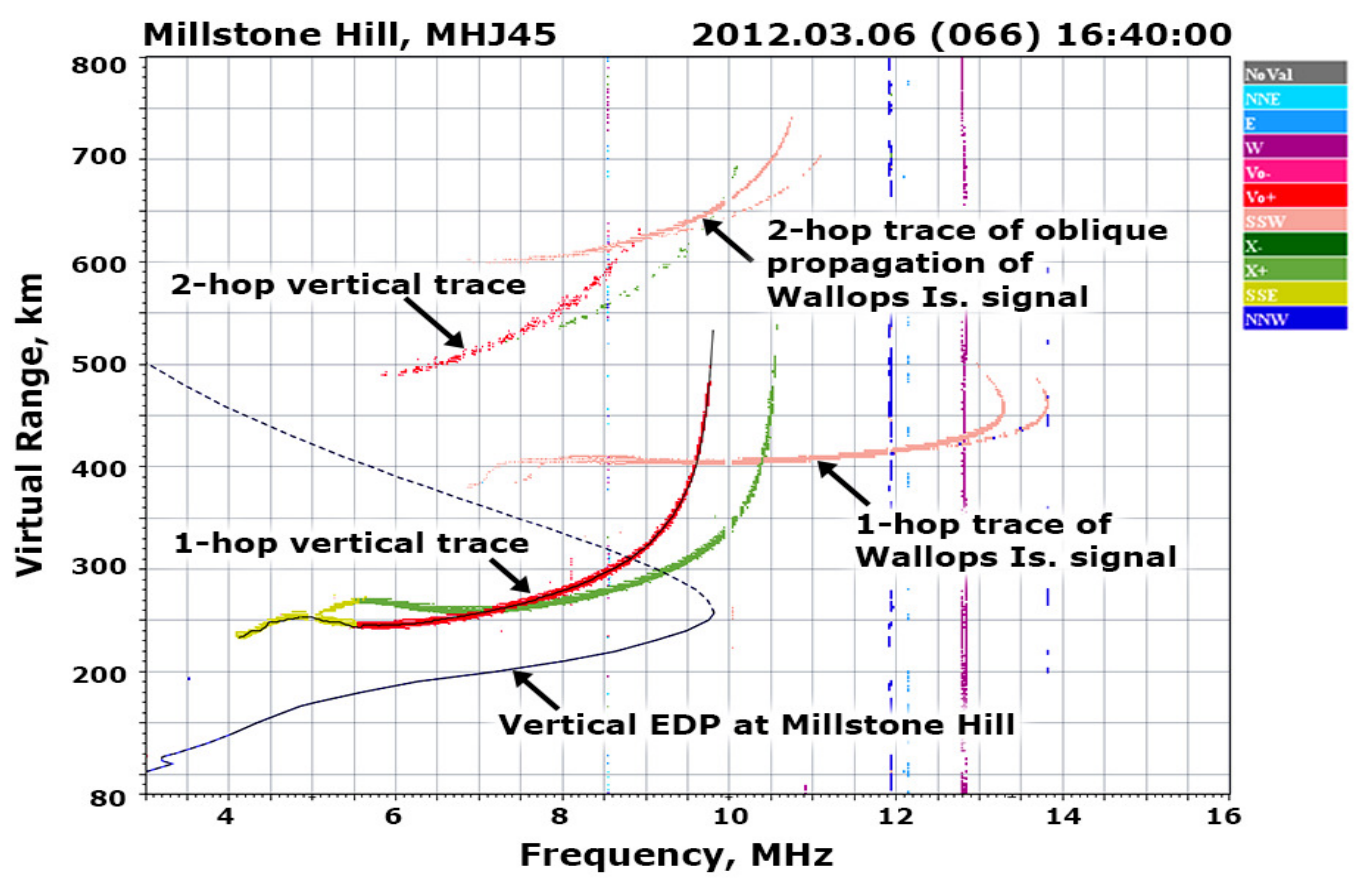

Figure 6: DPS4D ionogram at Millstone Hill showing oblique propagation signals from Wallops Is. 


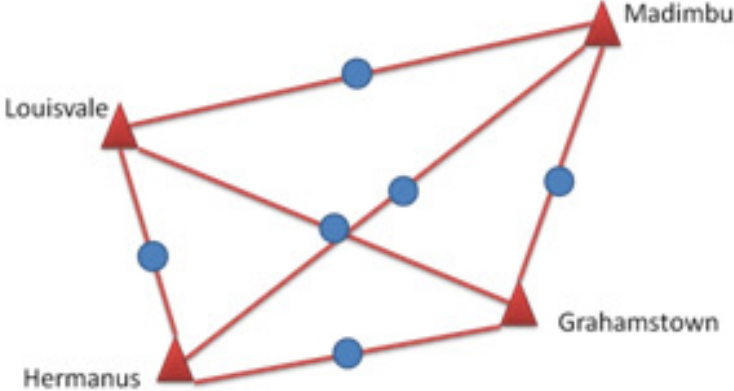

Figure 7a: Four-node constellation of DPS4D sounders in South Africa (triangles: sensor sites; circles: mid-points between sensors)

The VI ionogram autoscaler ARTIST5 (Galkin et al., 2008) has automatically identified the vertical echo traces and inverted them to the vertical electron density profile (EDP), ready for assimilation in ionospheric models. However, ARTIST5 does not have automatic oblique ionogram analysis capabilities, and the oblique echo traces currently still need to be manually scaled, precluding real-time assimilation. DPS4D ionogram data have the advantage of being tagged for the identification of the $\mathrm{O}$ and $\mathrm{X}$ polarizations for both the VI and OI echo traces. The identification of the echo polarization is done automatically by the DPS4D instrument, which can distinguish the rotation sense of the wave electric field in the recorded signal and tag it accordingly (red for $\mathrm{O}$ and green for $\mathrm{X}$ in Figure 6 and Figure 7). Autoscaling algorithms without $\mathrm{O} / \mathrm{X}$ tagging capability are less reliable as the echo tracing and ionogram interpretation tasks become significantly more difficult. Note that the oblique echo traces in Figure 6 and Figure 7 do not use "green color" for their X trace segments, which are clearly visible near the nose frequencies, instead the "azimuth angle of arrival color" is displayed for both the $\mathrm{O}$ and $\mathrm{X}$ oblique traces. The recorded oblique echoes do however contain the $\mathrm{O} / \mathrm{X}$-tagging information provided by the DPS4D.

Coordinated multi-node ionosonde networks like the 4-node DPS4D constellation in South Africa (Figure 7b) allows simultaneous registration of oblique signals from several transmitters, resulting roughly in a twofold enhancement of the

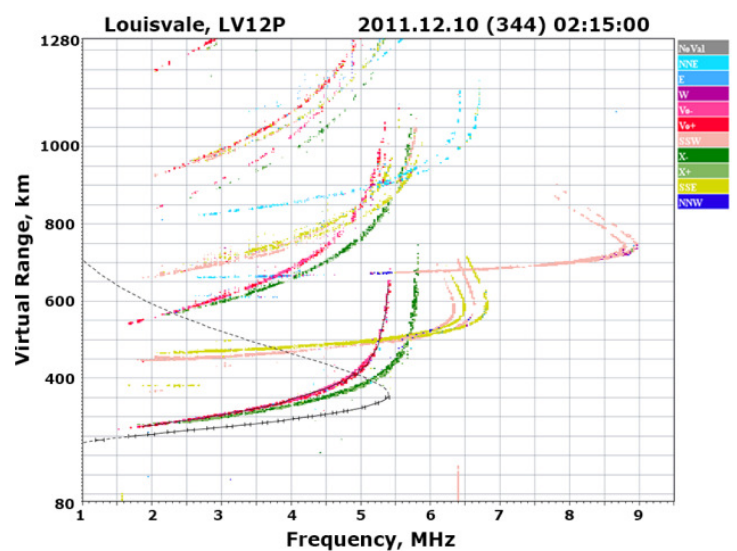

Figure 7b: Louisvale DPS4D ionogram showing oblique echo traces of transmissions from 3 partner DPS4Ds operating synchronously.

spatial resolution of ionospheric specification. The ground distances to Hermanus, Grahamstown, and Madimbo from Louisvale are $576 \mathrm{~km}, 727 \mathrm{~km}$, and 1,178 km, respectively. Note that the azimuth-angle colors are different for the oblique echo traces of the transmissions from Hermanus, Grahamstown, and Madimbo.

\subsection{LGDC: Lowell GIRO Data Center}

LGDC maintains a collection of computer software, database engines, and computer infrastructure for computations associated with RION nowcast and warning services, and open international data access for academia, students, radio enthusiasts, and space weather applications (Figure 8). Over 600 million records of sounding data are available over the GIRO Web Portal, http://giro.uml.edu. LGDC offers online interactive data explorer software tools for each of its database with capability to submit user-derived and annotation value-added information to LGDC.

Six databases comprise the core of LGDC (Figure 8). First introduced in 2003, Digital Ionogram Database "DIDBase" (Khmyrov et al., 2008) holds raw and derived data products associated with the VI ionogram mode of operation. Mated to DIDBase, Global Assimilative Model of Bottomside Ionosphere Timeline "GAMBIT" database stores historical records of IRTAM 3D model computations. Skymaps and associated raw and derived products (local ionospheric tilts and plasma drift velocities) are

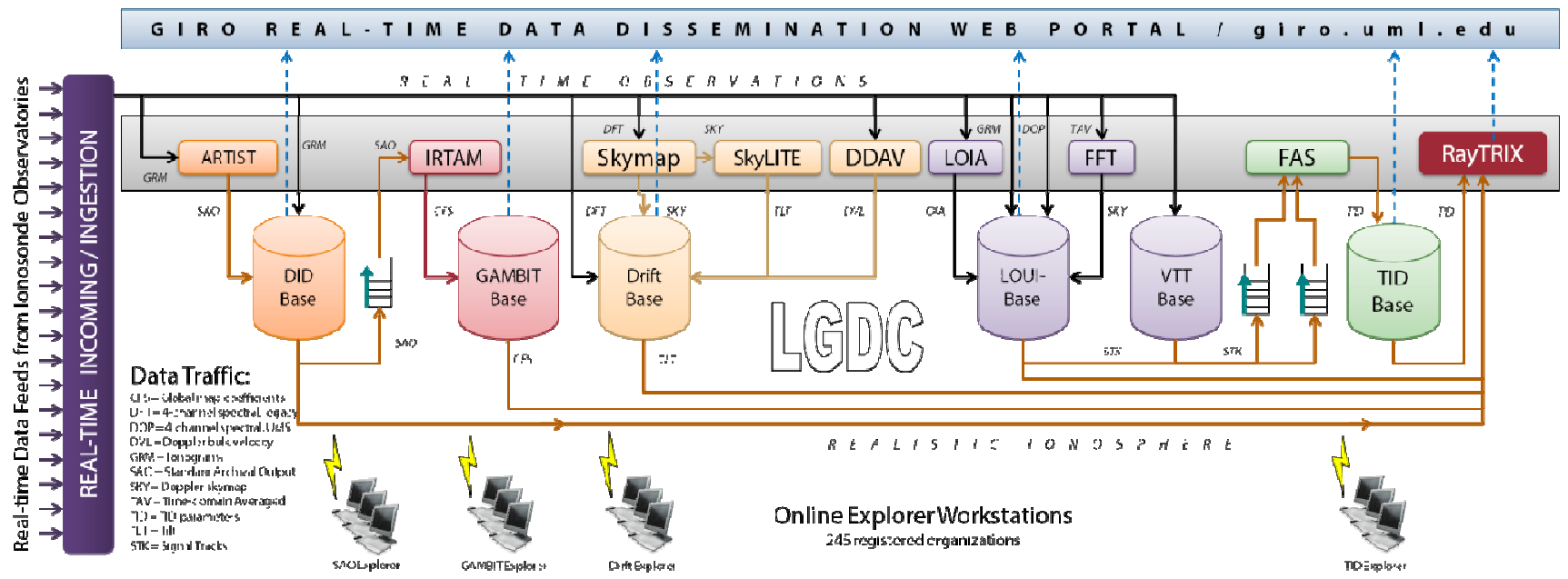

Figure 8: Computer infrastructure, databases, access portals, and data routes at Lowell GIRO Data Center. 
managed by DriftBase database. Oblique ionograms and records of signals from HF ground beacons are stored in the Lowell Oblique incidence Database (LOUI-Base). VI Tilt and TID (VTT) database holds raw data of high Doppler resolution fixedfrequency sounding, and TIDBase stores results of TID detection and evaluation. All databases are supplied with online "Explorer" software tools for expert-level data search, visualization, and interactive analysis, as well as the web portal for image browsing.

\section{Summary}

The RION suite is more than a multi-nation coordinated data sharing repository for experts: it is a wide-audience, high performance data center that synthesizes a live view of the current ionosphere and provides tools for its exploration and practical use. The RION data center manages a set of interconnected databases and intelligent system processors that accept live data feeds from the GIRO network of ionosondes for processing and dissemination. The IRTAM 3D model releases updated global ionospheric weather nowcast every 15 minutes, reports detected TID events to the warning service to alert end users, and aids raytracing software applications. Open data access to retrospective data collections allow multiple scientific study scenarios, educational outreach, and support of HF radio enthusiasts. Heavy investments of time, effort, expertise, and funds continue to be made to produce, collect, quality control, interpret, and archive ionosonde data for ISWI.

\section{Acknowledgements}

The authors gratefully acknowledge the contributions of the research and engineering personnel at Lowell Digisonde International and the University of Massachusetts Space Science Laboratory: Xueqin Huang, Alexander Kozlov, Ryan Hamel, David Kitrosser, and Chris Granz. Data from Jicamarca, Juliusruh, Pruhonice, Louisvale, and the Millstone Hill Digisonde observatories have been provided via agreements of the station owners with Lowell GIRO Data Center on open data sharing. I.G. and B.R. were, in part, supported by US Air Force grant FA8650-16-C-9104.

\section{References}

Altadill, D., Torta, J., and Blanch, E: 2009, Adv.Space Res. 43, 1825, doi: 10.1016/j.asr.2008.08.014

Bilitza, D., Radicella, S.M., Reinisch, B.W., Adeniyi, J.O., Mosert Gonzalez, M.E., Zhang, S.R., and Obrou, O: 2000, Adv. Space Res. 25, 89, doi: 10.1016/S0273-1177(99)00902-3.

Bilitza, D., Altadill, D., Truhlik, V., Shubin, V., Galkin, I., Reinisch, B., and Huang, X.: 2017, Space Weather 15, 418, doi: $10.1002 / 2016$ SW00159.

Croft, T.A. and Hoogasian, H.: 1968, Radio Sci. 3, 69.

Galkin, I.A., Khmyrov, G.M., Kozlov, A.V., Reinisch, B.W., Huang, X., and Paznukhov, V.V.: 2008, AIP Conf. Proc. 974, 150.

Galkin, I.A., Reinisch, B.W., Huang, X., and Bilitza, D.: 2012, Radio Sci. 47, RSOL07.

Hartman, W., Schmidt, W., and Galkin, I.A.: 2018, Proc. COSPAR2018, C4.1-0023-18.

Huang, X. and Reinisch, B.W.: 2001, Radio Sci. 36, 335.

Huang, X. and Reinisch, B.W.: 2006, Radio Sci. 41, RS5S47.

Khmyrov, G.M., Galkin, I.A., Kozlov, A.V., Reinisch, B.W., McElroy, J., and Dozois, C.: 2008, AIP Conf. Proc. 974, 175.

Paznukhov, V.V., Galushko, V.G., and Reinisch, B.W.: 2012, Adv. Space. Res. 49, 700, doi:10.1016/j.asr.2011.11.012.

Pezzopane, M., Scotto, C., Tomasik, L., and Krasheninnikov, I.: 2010, Acta Geophys. 58, 513, doi:10.2478/s11600-009-0038-1.

Piggott W.R. and Rawer, K., ed.: 1978, U.R.S.I. Handbook of Ionogram Interpretation and Reduction, WDC-A for STP Rep. UAG-23A, Boulder, CO.

Ramakrishnan, S. and Rawer, K.: 1972, in Bowhill S.A., et al. (ed.), Space Research XII, Akademie, Berlin, Germany, p. 1253.

Reinisch, B.W. and Huang, X.: 1983, Radio Sci. 18, 477, doi:10.1029/RS018i003p00477.

Reinisch, B.W. and Huang X.: 1998, Finding better B0 and B1 parameters for the IRI F2-profile function, Adv. Space Res., 22, 741-747.

Reinisch, B.W., Scali, J.L., and Haines, D.M.: 1998, Annali di Geofisica, 41, 695.

Reinisch, B.W., Huang, X., Galkin, I. A., et al.: 2005, J. Atmos. Solar-Terr. Physics, 67, 1054.

Reinisch, B.W., Galkin, I.A. Khmyrov G.M., et al.: 2009, doi:10.1029/2008RS004115.

Reinisch, B.W. and Galkin, I.A.: 2011, EPS 63, 377, doi:10.5047/eps.2011.03.001.

Reinisch, B.W., Galkin, I.A., Belehaki, A., et al.: 2018, Radio Sci., doi:10.1002/2017RS006263.

Sales, G.S., Reinisch, B.W., Scali, J.L., Dozois, C., Bullett, T.W., Weber, E.J., and Ning, P.: 1996, J. Geophys. Res. 101, 26,819, doi:10.1029/96JA01946.

Scali, J. L., Reinisch, B.W. , Heinselman, C.J. , and Bullett, T,: 1995, Radio Sci., 30, 1481.

Scotto, C,: 2009, Adv. Space Res.44, 756, doi:10.1002/2013RS005223.

Titheridge, J.E.: 1985, WDC-A for STP Rep. UAG-93, Boulder, CO, 194.

Vartanyan, A., Milikh, G.M., Papadopoulos, K., et al.: 2012, J. Geophys. Res., 117, A10307, doi:10.1029/2012JA017563.

Verhulst, T., Altadill, D., Mielich, J., Reinisch, B., Galkin, I., Mouzakis, A., Belehaki, A., Buresova, D., Stankov, S., Blanch, E., and Kouba, D.: 2017, Adv. Space Res., doi:10.1016/j.asr.2017.06.033.

Wright, J.W. and Pitteway, M. L. V.: 1998, WDC-A for STP Rep. UAG 105, 1.

Zabotin, N.A., Wright, J.W., and Zhbankov, G.A.: 2006, Radio Sci. $41, \mathrm{RS} 6 \mathrm{~S} 32$. 